\title{
Association between Glycemic Control in Patients with Diabetes and Mental Health Variables Including Depression
}

\author{
Hyun Lee, MD, Ji Hye Oh, MD, Yoo-Hyun Um, MD, PhD, Sung-Min Kim, MD, Tae-Won Kim, MD, \\ Ho-Jun Seo, MD, PhD, Seung-Chul Hong, MD, PhD, Jong-Hyun Jeong, MD, PhD \\ Department of Psychiatry, The Catholic University of Korea College of Medicine, Seoul, Korea
}

\begin{abstract}
Background: The purpose of this study was to measure several mental health variables according to HbA1c level and examine their relationship among diabetic patients.

Methods: Total 89 outpatients who attended diabetes education program at St. Vincent's Hospital, The Catholic University of Korea College of Medicine, were enrolled this study. The Beck Depression Inventory (BDI), State-Trait Anxiety Inventory, Stress Response Inventory (SRI), abbreviated version of World Health Organization Quality of Life assessment instrument (WHOQOL-BREF), Insomnia Severity Index, and Epworth Sleepiness Scale (ESS) were administered to all patients. Significant differences between groups were assessed by t-test and chi-squared test. Pearson correlation and multiple linear regression analyses were used to identify the variables that affect $\mathrm{HbA1c}$ levels.

Results: The well-controlled group had a significantly lower BDI score than the poorly controlled group. The wellcontrolled group also showed significantly lower SRI and ESS. HbA1c, BDI, SRI, and ESS were positively correlated. Duration and BDI were the only variables affecting HbA1c levels.

Conclusion: Emphasis should be given to the identification and management of mental health problems, including especially depressive symptoms in patients with diabetes.
\end{abstract}

Keywords Diabetes mellitus, Depression, Emotional stress, Anxiety

\section{INTRODUCTION}

Diabetes mellitus is one of the life-threatening diseases of the 21st century. The prevalence of diabetes worldwide is one in 11 adults [1]. Many diabetic patients may experience depressive and anxiety symptoms due to stress owing to the occurrence of diabetes, lifestyle changes to normalize blood sugar, use of drugs or insulin injections and diabetes-related complications [2].

The prevalence of depression among diabetic patients is known to be about twice as high as that of general population, reaching about $28.5 \%$ [3]. The prevalence of anxiety disorders increased in patients diagnosed with diabetes. Moreover, about $40 \%$ of diabetic patients present with clinically significant anxiety symptoms [4]. The depression and anxiety in diabetic patients may worsen the prognosis of diabetes by making the patients neglect selfcare, reducing treatment compliance [5] and quality of life [6], and increasing their mortality [7].

There have been studies on the correlation between diabetes and depression, but no common genetic factors have been found to affect the occurrence of both diseases $[8,9]$. It was suggested that diabetes and depression have a bidirectional relationship and share common risk

Received January 16, 2020, Revised February 21, 2020, Accepted February 27, 2020

Correspondence: Jong-Hyun Jeong, MD, PhD

Department of Psychiatry, St. Vincent's Hospital, The Catholic University of Korea College of Medicine, 93 Jungbu-daero, Paldal-gu, Suwon 16247, Korea

TEL +82-31-249-8038 FAX +82-31-248-6758 E-mail anton3@catholic.ac.kr ORCID https://orcid.org/0000-0003-3570-7607

Copyright (c) by Korean Society for Affective Disorders. All Rights reserved.

This is an Open Access article distributed under the terms of the Creative Commons Attribution Non-Commercial License (http://creativecommons.org/licenses/ by-nc/4.0/) which permits unrestricted non-commercial use, distribution, and reproduction in any medium, provided the original work is properly cited. 
factors $[10,11]$. In particular, the need for in-depth study of the common risk factors that can affect the development of type 2 diabetes and depression such as the low socioeconomic status [12,13], poor sleep quality [14,15], decreased physical activity $[16,17]$ and chronic stress [18] has been emphasized. Partial remission of depressive symptom has been reported after improvement of high blood sugar levels in diabetic patients [19].

Although glycemic control and depression are expected to be correlated with each other, previous studies have shown contradictory results regarding the association between depression and glycemic control [20,21]. It is also reported that diabetic patients have a higher prevalence of depression than the general population. However, fewer number of diabetic patients have been diagnosed with depression and have started treatment compared to the general population [22]. Therefore, it is thought that identification and evaluation of the psychopathology associated with HbAlc will have a major influence on mental health as well as glycemic control of diabetic patients. The aim of this study was to confirm the association between $\mathrm{HbAlc}$ and various psychopathologies including depression.

\section{MATERIALS AND METHODS}

\section{Study population}

This study is conducted based on face-to-face medical examinations and surveys of patients who participated in diabetes classes from July 2012 to January 2014 at St. Vincent's Hospital, The Catholic University of Korea. Patients with organic mental disorders, epilepsy, eating disorders, alcohol and other substance-related disorders, obsessive compulsive disorder and other severe acute physical illnesses were excluded. Eighty-nine subjects who were willing to participate in this study with written consent and did not meet the exclusion criteria were enrolled ( $\mathrm{n}=89$ ).

This study was approved by the Institutional Review Board (IRB No. VC12QISI0154) for Human Research of the St. Vincent's Hospital, The Catholic University of Korea.

\section{Evaluation}

All subjects were surveyed for age, sex, marital status, education, occupation, duration of diabetes, economic status and family history of diabetes with face-to-face medical examination and questionnaires. Education was classified as lower school graduate, middle school graduate, high school graduate, university graduate and postgraduate school graduate. Economic status was divided into upper, middle and lower class. Alcohol consumption status, smoking status, body mass index, current treatment status for diabetes, treatment method, and history of hospitalization due to diabetes were also investigated. Also, the presence of diabetic retinopathy and hypertension was assessed for complication status of diabetes. All subjects underwent basic blood tests and urine tests including fasting blood sugar, postprandial blood sugar, HbAlc, and total cholesterol level. Subjects with $\mathrm{HbAlc}$ level of less than $7 \%$ were classified as well-controlled group and subjects with HbAlc level of $7 \%$ or higher were classified as poorly controlled group according to the target $\mathrm{HbAlc}$ level of $7 \%$ recommended by the American Diabetes Association.

Depression in diabetics was assessed with Beck Depression Inventory (BDI). Anxiety was assessed with State-Trait Anxiety Inventory, and stress was assessed with Stress Response Inventory (SRI). The quality of life of the patients was assessed with an abbreviated version of World Health Organization Quality of Life assessment instrument (WHOQOL-BREF) published by the World Health Organization. The WHOQOL-BREF consists of 26 items: overall QOL and general health, each with 4 subdomains of physical health, psychological health, social relationships and environment. Twentysix items were assessed in five scales, scoring from 1 (not at all) to 5 (completely), where higher score indicates a more positive response to quality of life.

The Korean version of the Insomnia Severity Index (ISI-K) [23] was used to evaluate sleeping disorder. A questionnaire about snoring and uncomfortable leg sensation was added for a detailed assessment of insomnia symptoms. The four following questionnaire items were assessed in 5 scales, scoring 0 (not at all) to 4 (very much) for snoring: 1. Presence of snoring, 2. Snoring bothers other people, 3. Witnessed apnea during sleep, 4. Feeling drowsy, fatigued, or not up to par during wake time. The higher the sum of the scores was, the more severe the snoring was considered. The subjects were also evaluated for disturbance of sleep by uncomfortable leg sensation before entering sleep in 5 scales, scoring from 0 (not at all) to 4 (very much). The severity of daytime 
sleepiness symptoms was assessed using the Epworth Sleepiness Scale (ESS).

\section{Statistical analysis}

Collected data was analyzed using PASW Statistics for Windows, Version 18.0 (SPSS Inc., Chicago, IL, USA). Any value of $p<0.05$ was considered statistically significant. The subjects were divided into well-controlled group $(\mathrm{HbAlc}<7 \%)$ and poorly controlled group (HbAlc $\geq 7 \%$ ) according to their HbAlc level. t-test and chi-square test were used to compare the mental health variables such as demographic characteristics, clinical variables related to diabetes treatment, depression, anxiety, stress, quality of life, and sleep disorder between the two groups. Pearson's correlation coefficient was used to analyze the correlation between the HbAlc level and mental health variables. Also, multiple linear regression analysis was used to identify the variables that affect the HbAlc.

\section{RESULTS}

\section{Demographic and clinical characteristics}

A total of 89 subjects were enrolled. Forty-three subjects were categorized as well-controlled group and the other 46 as poorly controlled group. The HbAlc level was $6.22 \pm 0.41$ in the well-controlled group and $8.80 \pm 1.96$ in the poorly controlled group. The difference between the two groups was significant $(p<0.001)$. The duration of disease was $4.88 \pm 10.12$ months in the wellcontrolled group and $41.41 \pm 66.95$ months in the poorly controlled group. The difference between the two groups was significant $(\mathrm{p}=0.010)$. In addition, there was no significant difference between the two groups in terms of age, sex, education, occupation, marital status, economic status, family history of diabetes, alcohol consumption and smoking status (Table 1).

As for the treatment of diabetes in the well-controlled group, 24 patients (55.8\%) were being untreated. Fourteen patients $(32.6 \%)$ were being treated with oral hypoglycemic agents, 3 patients $(7.0 \%)$ with insulin injections, and 2 patients $(4.7 \%)$ with both oral hypoglycemic agents and insulin injections. In the poorly controlled group, 9 patients $(19.6 \%)$ were being untreated. Nine patients $(19.6 \%)$ were being treated with oral hypoglyce- mic agents, 19 patients (41.3\%) with insulin injections, and 9 patients $(19.6 \%)$ were being treated with both oral hypoglycemic agents and insulin injections. The difference between the two groups was significant $(\mathrm{p}=0.002)$. Regarding the patients with hospitalization experience

Table 1. Demographic characteristics of study participants $(n=89)$

\begin{tabular}{|c|c|c|c|}
\hline Variable & $\begin{array}{c}\text { Well } \\
\text { controlled } \\
\text { group }(n=43)\end{array}$ & $\begin{array}{c}\text { Poorly } \\
\text { controlled } \\
\text { group }(n=46)\end{array}$ & $p$-value \\
\hline $\mathrm{HbA1c}$ & $6.22 \pm 0.41$ & $8.80 \pm 1.96$ & $<0.001 *$ \\
\hline Age (y) & $53.09 \pm 9.78$ & $51.80 \pm 10.42$ & 0.550 \\
\hline Duration (mo) & $4.88 \pm 10.12$ & $41.41 \pm 66.95$ & $0.001 *$ \\
\hline \multicolumn{4}{|l|}{ Sex } \\
\hline Male & $17(39.5)$ & $21(45.7)$ & 0.560 \\
\hline Female & $26(60.5)$ & $25(54.3)$ & \\
\hline BMI & $25.80 \pm 4.28$ & $24.37 \pm 3.57$ & 0.091 \\
\hline \multicolumn{4}{|l|}{ Education (y) } \\
\hline Elementary & $4(9.3)$ & $0(0.0)$ & 0.162 \\
\hline Middle School & $5(11.6)$ & $7(15.2)$ & \\
\hline High school & $25(58.1)$ & $24(52.2)$ & \\
\hline College & $9(20.9)$ & $14(30.4)$ & \\
\hline Graduate school & $0(0.0)$ & $1(2.2)$ & \\
\hline \multicolumn{4}{|l|}{ Occupation } \\
\hline Yes & $21(48.8)$ & $21(45.7)$ & 0.764 \\
\hline No & $22(21.2)$ & $25(54.3)$ & \\
\hline \multicolumn{4}{|l|}{ Marital status } \\
\hline Single & $0(0.0)$ & $3(6.5)$ & 0.242 \\
\hline Married & $42(97.7)$ & $41(89.1)$ & \\
\hline Separate/divorced & $1(2.3)$ & $1(2.2)$ & \\
\hline Bereaved & $0(0.0)$ & $1(2.2)$ & \\
\hline \multicolumn{4}{|l|}{ SES } \\
\hline High & $1(2.3)$ & $1(2.2)$ & 0.897 \\
\hline Middle & $32(74.4)$ & $36(78.3)$ & \\
\hline Low & $10(23.3)$ & $9(19.6)$ & \\
\hline \multicolumn{4}{|l|}{ DM family history } \\
\hline Yes & $22(51.2)$ & $18(39.1)$ & 0.254 \\
\hline No & $21(48.8)$ & $28(67.4)$ & \\
\hline \multicolumn{4}{|l|}{ Alcohol } \\
\hline Yes & $14(32.6)$ & $15(32.6)$ & 0.996 \\
\hline No & $29(67.4)$ & $31(67.4)$ & \\
\hline \multicolumn{4}{|l|}{ Smoking } \\
\hline Yes & $4(9.3)$ & $11(23.9)$ & 0.066 \\
\hline No & $39(90.7)$ & $35(76.1)$ & \\
\hline
\end{tabular}

Values are presented as mean \pm standard deviation or number (\%).

BMI, body mass index; SES, socioeconomic status; DM, diabetes mellitus.

*p<0.05 by independent $t$-test or chi-square test. 
for diabetes, 19 subjects $(41.3 \%)$ of the poorly controlled group were significantly larger in number compared to 5 subjects $(11.6 \%)$ of the well-controlled group $(\mathrm{p}=0.002)$. Fasting blood glucose $(134.84 \pm 49.72$ vs. $176.11 \pm 63.22$, $\mathrm{p}=0.001$ ) and 2-hour postprandial blood glucose $(223.02 \pm 92.47$ vs. $306.28 \pm 102.55, \mathrm{p}<0.001)$ were significantly higher in the poorly controlled group (Table 2 ).

\section{Mental health variables regarding $\mathrm{HbA1}$ c level}

The characteristics of mental health variables regarding the HbAlc level are shown in Table 3. The BDI and SRI of the poorly controlled group were significantly higher compared to those of well-controlled group with a p-value of 0.031 and 0.030 , respectively. The ESS of the well-controlled group was significantly higher than that of poorly controlled group $(\mathrm{p}=0.036)$

\section{Correlation between $\mathrm{HbA} 1 \mathrm{c}$ level and mental health variables}

A correlation analysis was performed between $\mathrm{HbAlc}$ and mental health variables (Table 4). It was confirmed that BDI $(\gamma=0.265, p=0.012)$, SRI $(\gamma=0.214, p=0.044)$, ESS $(\gamma=0.340, p=0.001)$ had a significant positive correlation with $\mathrm{HbAlc}$

The correlation analysis between HbAlc and physical health of WHOQOL-BREF showed a significant negative correlation with a correlation coefficient $\gamma$ value of -0.229 and a p-value of 0.031 . There also was a significant positive correlation between $\mathrm{HbAlc}$ and uncomfortable leg sensation $(\gamma=0.223, \mathrm{p}=0.036)$.

\section{Association between $\mathrm{HbA1c}$ level and mental health variables}

Multiple linear regression analysis was performed to identify the correlation between HbAlc and five variables that may affect glycemic control including BMI,

Table 2. Clinical characteristics of study participants $(n=89)$

\begin{tabular}{|c|c|c|c|}
\hline Variable & Well controlled group $(n=43)$ & Poorly controlled group $(n=46)$ & $p$-value \\
\hline \multicolumn{4}{|l|}{ Treatment } \\
\hline $\mathrm{OHA}$ & $2(4.7)$ & $9(19.6)$ & $0.002 \star$ \\
\hline Insulin & $14(32.6)$ & $19(41.3)$ & \\
\hline OHA+insulin & $3(7.0)$ & $9(19.6)$ & \\
\hline None & $24(55.8)$ & $9(19.6)$ & \\
\hline DM related Admission history & $5(11.6)$ & $19(41.3)$ & $0.002 \star$ \\
\hline \multicolumn{4}{|l|}{ Complication } \\
\hline Diabetic retinopathy & $6(14.0)$ & $9(19.6)$ & 0.480 \\
\hline Hypertension & $18(41.9)$ & $12(26.1)$ & 0.116 \\
\hline FBS & $134.84 \pm 49.72$ & $176.11 \pm 63.22$ & $0.001 *$ \\
\hline PP2 & $223.02 \pm 92.47$ & $306.28 \pm 102.55$ & $<0.001 *$ \\
\hline Total cholesterol (mg/dL) & $190.05 \pm 43.41$ & $172.41 \pm 45.51$ & 0.065 \\
\hline Triglyceride (mg/dL) & $132.95 \pm 85.30$ & $125.72 \pm 79.91$ & 0.680 \\
\hline HDL-cholesterol (mg/dL) & $44.38 \pm 10.41$ & $42.59 \pm 8.47$ & 0.373 \\
\hline BUN & $16.16 \pm 4.60$ & $18.40 \pm 7.31$ & 0.090 \\
\hline Serum creatinine & $0.78 \pm 0.18$ & $0.78 \pm 0.25$ & 0.904 \\
\hline \multicolumn{4}{|l|}{ Proteinuria } \\
\hline Positive & $4(9.3)$ & $6(13.0)$ & 0.869 \\
\hline Negative & $38(88.4)$ & $39(84.8)$ & \\
\hline False positive & $1(2.3)$ & $1(2.2)$ & \\
\hline
\end{tabular}

Values are presented as number (\%) or mean \pm standard deviation.

OHA, oral hypoglycemic agent; DM, diabetes mellitus; FBS, fasting blood sugar; PP2, post prandial 2-hour blood sugar; HDL-cholesterol, high density lipoprotein cholesterol; BUN, blood urea nitrogen.

$\star p<0.05$ by independent $t$-test or chi-square test. 
Hyun Lee, et al. Mental Health Variables Influencing Glycemic Control

Table 3. Comparison of mental health variables between well-controlled group and poorly controlled group

\begin{tabular}{|c|c|c|c|}
\hline Variable & Well controlled group $(n=43)$ & Poorly controlled group $(n=46)$ & $p$-value \\
\hline \multicolumn{4}{|l|}{ WHOQOL-BREF } \\
\hline physical health domain & $23.86 \pm 4.22$ & $22.52 \pm 4.11$ & 0.133 \\
\hline Psychological domain & $18.33 \pm 3.56$ & $17.02 \pm 3.51$ & 0.086 \\
\hline Social relationships domain & $9.81 \pm 1.87$ & $9.37 \pm 1.79$ & 0.255 \\
\hline Environment domain & $24.37 \pm 4.15$ & $23.96 \pm 4.11$ & 0.636 \\
\hline $\mathrm{BDI}$ & $10.79 \pm 8.83$ & $15.22 \pm 10.15$ & $0.031 *$ \\
\hline SA & $42.00 \pm 5.92$ & $42.15 \pm 6.40$ & 0.908 \\
\hline TA & $41.16 \pm 6.00$ & $42.09 \pm 7.72$ & 0.532 \\
\hline SRI & $20.05 \pm 20.91$ & $36.65 \pm 29.29$ & $0.003 *$ \\
\hline ISI-K & $5.86 \pm 6.23$ & $8.00 \pm 5.77$ & 0.096 \\
\hline Snoring & $3.35 \pm 3.65$ & $3.24 \pm 2.57$ & 0.871 \\
\hline Uncomfortable leg sensation & $0.40 \pm 0.66$ & $0.70 \pm 1.49$ & 0.218 \\
\hline ESS & $6.07 \pm 2.69$ & $7.78 \pm 4.67$ & $0.036 *$ \\
\hline
\end{tabular}

Values are presented as mean \pm standard deviation.

WHOQOL-BREF, abbreviated version of World Health Organization Quality of Life assessment instrument; BDI, Beck Depression Inventory; SA, state anxiety; TA, trait anxiety; SRI, stress response inventory; ISI-K, Korean version of the Insomnia Severity Index; ESS, Epworth Sleepiness Scale.

$\star p<0.05$ by independent $t$-test.

Table 4. Correlation between $\mathrm{HbA1c}$ and several mental health variables

\begin{tabular}{|c|c|c|}
\hline \multirow{2}{*}{ Variable } & \multicolumn{2}{|c|}{$\mathrm{HbA1c}$} \\
\hline & $\gamma$ & $p$-value \\
\hline \multicolumn{3}{|l|}{ WHOQOL-BREF } \\
\hline Physical health domain & -0.229 & $0.031 *$ \\
\hline Psychological domain & -0.200 & 0.060 \\
\hline Social relationships domain & -0.105 & 0.330 \\
\hline Environment domain & -0.112 & 0.294 \\
\hline $\mathrm{BDI}$ & 0.265 & $0.012 *$ \\
\hline SA & -0.001 & 0.992 \\
\hline TA & 0.058 & 0.592 \\
\hline SRI & 0.214 & $0.044 \star$ \\
\hline ISI-K & 0.106 & 0.321 \\
\hline Snoring & -0.127 & 0.234 \\
\hline Uncomfortable leg sensation & 0.223 & $0.036 *$ \\
\hline ESS & 0.340 & $0.001 *$ \\
\hline
\end{tabular}

These data represent Pearson's correlation coefficients $(\gamma)$. WHOQOL-BREF, abbreviated version of World Health Organization Quality of Life assessment instrument; BDI, Beck Depression Inventory; SA, state anxiety; TA, trait anxiety; SRI, stress response inventory; ISI-K, Korean version of the Insomnia Severity Index; ESS, Epworth Sleepiness Scale. * $<<0.05$ by Pearson's correlation test. duration, BDI, state anxiety, and trait anxiety. In regression analysis, $\mathrm{R}^{2}$ was 0.210 and $\mathrm{F}$ statistic was 4.411 $(\mathrm{p}=0.001)$, indicating that the regression model is appropriate. Duration $(\beta=0.350, T=3.474, p=0.001)$ and BDI ( $\beta=0.266, T=2.330, p=0.022)$ were the only variables affecting the HbAlc (Table 5).

\section{DISCUSSION}

Our results showed that depression and stress response were significantly higher in the poorly controlled group with high HbAlc level. Also, the subject of the poorly controlled group had more severe symptoms of daytime sleepiness. The HbAlc level and the quality of life of the physical health domain of WHOQOL-BBREF had a negative correlation. The HbAlc level had a positive correlation with depressive symptom, stress response, and daytime sleepiness. Also, disease duration and depression were the variables affecting the HbAlc.

Based on this study, HbAlc level of diabetic patients seems to be associated with depression. There are ongoing studies on the correlation between type 2 diabetes and depression. In many studies, the correlation between the two diseases has been suggested in the following three possible directions.

First, we can consider the common factors associated 
Table 5. Association between $\mathrm{HbA1c}$ and duration, depressive and anxiety symptoms

\begin{tabular}{lccccccc}
\hline \multirow{2}{*}{ Variable } & $\mathrm{B}$ & \multicolumn{8}{c}{ HbA1c } \\
\cline { 3 - 7 } & & $\beta$ & $\mathrm{T}$ & $\mathrm{p}$-value & F-value $(\mathrm{p})$ & $\mathrm{R}$ & $\mathrm{R}^{2}$ \\
\hline BMI & -0.046 & -0.097 & -0.978 & 0.331 & $4.411(0.001 *)$ & 0.458 & 0.210 \\
Duration & 0.013 & 0.350 & 3.474 & $0.001 *$ & & \\
BDI & 0.053 & 0.266 & 2.330 & $0.022 \star$ & & \\
SA & 0.026 & 0.084 & 0.733 & 0.465 & & \\
TA & -0.031 & -0.111 & -0.866 & 0.389 & & \\
\hline
\end{tabular}

$\mathrm{BMI}$, body mass index; BDI, Beck Depression Inventory; SA, state anxiety; TA, trait anxiety.

$\star p<0.05$ by multiple linear regression analysis.

with the development of diabetes and depression. Chronic stress activates the hypothalamic-pituitary-adrenal axis (HPA-axis) and stimulates the sympathetic nervous system. This increases the production of cortisol in the adrenal cortex and promotes the release of adrenaline and noradrenaline in the adrenal medulla [24]. The sustained release of these hormones and sympathetic hyperactivity can lead to insulin resistance in the body, which is a characteristic pathogenesis of type 2 diabetes [24]. In addition, chronic stress causes the immune response to increase the production of inflammatory cytokines. These inflammatory cytokines interact with pancreatic $\beta$-cells to induce insulin resistance, leading to development of type 2 diabetes [25]. Furthermore, stress can increase the secretion of cortisol in hypothalamus and pituitary gland by promoting synthesis of pre-inflammatory cytokines such as Interleukin-6, Tumor necrosis factor- $\alpha$, and Interferon- $\gamma$ from immune tissues and cells through inflammatory reactions [26,27], resulting in increased insulin resistance [28]. Therefore, chronic stress may activate common pathways that may promote type 2 diabetes and depression.

Second, depression itself may increase the risk of developing diabetes. Previous studies have shown significant increase in incidence of type 2 diabetes in depressed patients [29]. A meta-analysis conducted in 2006 reported that depressed adults had 37\% increase in risk of developing type 2 diabetes [30]. One study demonstrated a significant improvement in insulin resistance after treatment of depression [31]. Another study showed that noradrenalinergic antidepressants lowered insulin sensitivity in normal controls [32]. In 2013, a meta-analysis published in Korea reported that the selective serotonin reuptake inhibitors and tricyclic antidepressants increased the risk of type 2 diabetes [33]. However, the pathophysiological mechanisms of how depression con- tributes to the development of diabetes are still unclear. Therefore, further study on the effects of antidepressants on blood sugar control in patients with major depression is needed.

Third, diabetes may increase the chance of depression. A meta-analysis released in 2010 reported that the patients with type 2 diabetes had $24 \%$ increase in risk for developing depression compared to the general population [34]. However, an increased prevalence of depression was observed in pre-diabetic patients and undiagnosed diabetic patients compared to the controls with normal blood glucose levels in another study [35]. Thus, there may be other mechanisms by which diabetes increase risk of developing depression. There are many ongoing studies evaluating the association between depression of diabetic patient and biochemical changes of the brain caused by diabetes. A systematic review published in 2006 suggested that diabetes is associated with cerebral atrophy, lacunar infarction, and local changes in cerebral blood flow [36]. Also, in one study, the size of hippocampus was significantly smaller in the diabetics group compared to the control group of similar age, sex, and education level. The study reported that HbAlc has a negative correlation with the size of hippocampus [37]. These structural changes are similar to the neurodegenerative changes that cause hippocampal atrophy in depressed patients [38]. Thus, further study of the relationship between the two diseases is needed.

Type 1 diabetes is characterized by the destruction of pancreatic $\beta$-cells by autoimmune mechanisms resulting in deficiency of insulin. There are relatively few studies on the association between type 1 diabetes and depression. A brain magnetic resonance spectroscopy video study showed that glutamate is increased in the prefrontal lobe with the increase of blood glucose in patients with type 1 diabetes, which is positively correlated with 
depressive symptoms in patients with type 1 diabetes [39]. Similar to type 2 diabetes, the autoimmune-related cytokines have been reported to not only activate the HPA-axis but also induce inflammatory responses found in depression of type 1 diabetics [40]. In this study, the severity of stress response and depressive symptom regarding the HbAlc level increased with difficulty in controlling blood glucose. This seems to be in agreement with previous studies.

In our study, there was no significant difference in severity of insomnia between the well-controlled group and poorly controlled group. In both groups, ISI-K score was less than 15.5 , and they had no clinically significant insomnia [23]. These findings did not support previous studies showing that patients with type 1 and type 2 diabetes have a higher incidence of insomnia than the general population $[41,42]$. Also, snoring implemented for additional evaluation of sleep disorder and the subjective sleep deterioration due to the uncomfortable leg sensation was not significantly different between the two groups. However, the daytime sleepiness evaluated with ESS was more severe in the poorly controlled group compared to the well-controlled group. The severity of daytime sleepiness was found to be positively correlated with the HbAlc level. This study showed no significant difference in sleep-related symptoms, including insomnia, snoring and uncomfortable leg sensation between the two groups. The more severe daytime sleepiness in the poorly controlled group is thought to be caused by lethargy, fatigue, or hypersomnia that can be accompanied by depressed mood. The daytime sleepiness in poorly controlled group may be associated with fatigue that may occur in diabetic patients. Warren et al. [43] argued that $90 \%$ of diabetic patients experience the multiple physical or psychological symptoms with high blood sugar. They also reported that among these symptoms, fatigue is one of the most common symptoms. Some studies have reported that chronic high blood sugar conditions in diabetes can cause fatigue [44]. This is consistent with the results of our study that the higher the HbAlc, the lower the quality of life with regards to physical health. Daytime sleepiness may make it difficult for diabetic patients to perform selfcare, such as exercise or diet therapy [45]. This may cause difficulty in blood sugar management and increased incidence of complications, which requires careful management.

Our study has several limitations. First, it is limited to generalize our results to all diabetic patients because the study is conducted of a small number of participants from a single institute. Second, because there is no normal control group, the prevalence of depression and anxiety is difficult to be compared with the actual control group represented by the general population. Third, there is limitation for elucidating the causality of temporal relationships between the changes in blood sugar levels and the mental health variables because this study is a cross-sectional study. Fourth, standardized evaluation tools were not used for assessment of uncomfortable leg sensation; also, objective evaluation such as polysomnography was not performed for sleep status assessment. Lastly, a self-reported subjective evaluation scale was used for assessment of depression and anxiety symptoms.

Nevertheless, this study identified the mental health variables related to glycemic control in diabetic patients. In other words, it was concluded that depression, as well as disease duration, can have a negative effect on glycemic control in diabetic patients. Therefore, evaluation and active treatment of depressive symptoms is important in treatment of diabetes.

\section{CONFLICTS OF INTEREST}

The authors have nothing to disclose.

\section{ORCID}

Hyun Lee
https://orcid.org/0000-0002-8969-0241
Ji Hye Oh
https://orcid.org/0000-0002-6865-3935
Yoo-Hyun Um
https://orcid.org/0000-0002-3403-4140
Sung-Min Kim
https://orcid.org/0000-0002-3082-4014
Tae-Won Kim
https://orcid.org/0000-0003-2689-202X
Ho-Jun Seo
https://orcid.org/0000-0003-1661-1394
Seung-Chul Hong
https://orcid.org/0000-0003-0828-2906
Jong-Hyun Jeong
https://orcid.org/0000-0003-3570-7607




\section{REFERENCES}

1. Ogurtsova K, da Rocha Fernandes JD, Huang Y, Linnenkamp U, Guariguata L, Cho NH, et al. IDF Diabetes Atlas: global estimates for the prevalence of diabetes for 2015 and 2040. Diabetes Res Clin Pract 2017;128:40-50.

2. Okamura F, Tashiro A, Utumi A, Imai T, Suchi T, Tamura D, et al. Insulin resistance in patients with depression and its changes during the clinical course of depression: minimal model analysis. Metabolism 2000;49:1255-60.

3. Anderson RJ, Freedland KE, Clouse RE, Lustman PJ. The prevalence of comorbid depression in adults with diabetes: a meta-analysis. Diabetes Care 2001;24:1069-78.

4. Grigsby AB, Anderson RJ, Freedland KE, Clouse RE, Lustman PJ. Prevalence of anxiety in adults with diabetes: a systematic review. J Psychosom Res 2002;53:1053-60.

5. Gonzalez JS, Peyrot M, McCarl LA, Collins EM, Serpa L, Mimiaga MJ, et al. Depression and diabetes treatment nonadherence: a meta-analysis. Diabetes Care 2008;31:2398403.

6. Baumeister H, Hutter N, Bengel J, Härter M. Quality of life in medically ill persons with comorbid mental disorders: a systematic review and meta-analysis. Psychother Psychosom 2011;80:275-86.

7. Egede LE, Nietert PJ, Zheng D. Depression and all-cause and coronary heart disease mortality among adults with and without diabetes. Diabetes Care 2005;28:1339-45.

8. Samaan Z, Garasia S, Gerstein HC, Engert JC, Mohan V, Diaz R, et al. Lack of association between type 2 diabetes and major depression: epidemiologic and genetic evidence in a multiethnic population. Transl Psychiatry 2015;5:e618.

9. Scherrer JF, Xian H, Lustman PJ, Franz CE, McCaffery J, Lyons MJ, et al. A test for common genetic and environmental vulnerability to depression and diabetes. Twin Res Hum Genet 2011;14:169-72.

10. Berge LI, Riise T. Comorbidity between type 2 diabetes and depression in the adult population: directions of the association and its possible pathophysiological mechanisms. Int J Endocrinol 2015;2015:164760.

11. Moulton CD, Pickup JC, Ismail K. The link between depression and diabetes: the search for shared mechanisms. Lancet Diabetes Endocrinol 2015;3:461-71.

12. Folb N, Lund C, Fairall LR, Timmerman V, Levitt NS, Steyn K, et al. Socioeconomic predictors and consequences of depression among primary care attenders with noncommunicable diseases in the Western Cape, South Africa: cohort study within a randomised trial. BMC Public Health 2015;15:1194.

13. Agardh E, Allebeck P, Hallqvist J, Moradi T, Sidorchuk A. Type 2 diabetes incidence and socio-economic position: a systematic review and meta-analysis. Int J Epidemiol 2011;40:804-18.

14. Vgontzas AN, Liao D, Pejovic S, Calhoun S, Karataraki M, Bixler EO. Insomnia with objective short sleep duration is associated with type 2 diabetes: a population-based study. Diabetes Care 2009;32:1980-5.

15. Walsh JK. Clinical and socioeconomic correlates of insomnia. J Clin Psychiatry 2004;65 Suppl 8:13-9.

16. Carnethon MR, Biggs ML, Barzilay JI, Smith NL, Vaccarino $\mathrm{V}$, Bertoni $\mathrm{AG}$, et al. Longitudinal association between depressive symptoms and incident type 2 diabetes mellitus in older adults: the cardiovascular health study. Arch Intern Med 2007;167:802-7.

17. Carnethon MR, Kinder LS, Fair JM, Stafford RS, Fortmann SP. Symptoms of depression as a risk factor for incident diabetes: findings from the National Health and Nutrition Examination Epidemiologic Follow-up Study, 1971-1992. Am J Epidemiol 2003;158:416-23.

18. Golden SH. A review of the evidence for a neuroendocrine link between stress, depression and diabetes mellitus. Curr Diabetes Rev 2007;3:252-9.

19. Testa MA, Simonson DC. Health economic benefits and quality of life during improved glycemic control in patients with type 2 diabetes mellitus: a randomized, controlled, double-blind trial. JAMA 1998;280:1490-6.

20. Egede LE, Ellis C. The effects of depression on metabolic control and quality of life in indigent patients with type 2 diabetes. Diabetes Technol Ther 2010;12:257-62.

21. Eren I, Erdi O, Sahin M. The effect of depression on quality of life of patients with type II diabetes mellitus. Depress Anxiety 2008;25:98-106.

22. Goldman LS, Nielsen NH, Champion HC. Awareness, diagnosis, and treatment of depression. J Gen Intern Med 1999;14:569-80.

23. Cho YW, Song ML, Morin CM. Validation of a Korean version of the insomnia severity index. J Clin Neurol 2014;10:210-5.

24. Kyrou I, Tsigos C. Stress hormones: physiological stress and regulation of metabolism. Curr Opin Pharmacol 2009;9:787-93.

25. Wang X, Bao W, Liu J, Ouyang YY, Wang D, Rong S, et al. Inflammatory markers and risk of type 2 diabetes: a systematic review and meta-analysis. Diabetes Care 2013;36:16675.

26. Maes M, Song C, Lin A, De Jongh R, Van Gastel A, Kenis $\mathrm{G}$, et al. The effects of psychological stress on humans: increased production of pro-inflammatory cytokines and a Th1-like response in stress-induced anxiety. Cytokine 1998;10:313-8.

27. Goebel MU, Mills PJ, Irwin MR, Ziegler MG. Interleukin-6 and tumor necrosis factor-alpha production after acute psychological stress, exercise, and infused isoproterenol: differential effects and pathways. Psychosom Med 2000;62:591-8.

28. Raison CL, Capuron L, Miller AH. Cytokines sing the blues: inflammation and the pathogenesis of depression. Trends Immunol 2006;27:24-31.

29. Holt RI, Phillips DI, Jameson KA, Cooper C, Dennison EM, Peveler RC; Hertfordshire Cohort Study Group. The 
relationship between depression and diabetes mellitus: findings from the Hertfordshire Cohort Study. Diabet Med 2009;26:641-8.

30. Knol MJ, Twisk JW, Beekman AT, Heine RJ, Snoek FJ, Pouwer F. Depression as a risk factor for the onset of type 2 diabetes mellitus. A meta-analysis. Diabetologia 2006;49:837-45.

31. Asghar S, Magnusson A, Hussain A, Diep LM, Bhowmik B, Thorsby PM. Depression and insulin resistance in nondiabetic subjects: an intervention study with insulin clamp technique. Int J Clin Med 2012;3:575-81.

32. McIntyre RS, Soczynska JK, Konarski JZ, Kennedy SH. The effect of antidepressants on glucose homeostasis and insulin sensitivity: synthesis and mechanisms. Expert Opin Drug Saf 2006;5:157-68.

33. Yoon JM, Cho EG, Lee HK, Park SM. Antidepressant use and diabetes mellitus risk: a meta-analysis. Korean J Fam Med 2013;34:228-40.

34. Nouwen A, Winkley K, Twisk J, Lloyd CE, Peyrot M, Ismail $\mathrm{K}$, et al. Type 2 diabetes mellitus as a risk factor for the onset of depression: a systematic review and metaanalysis. Diabetologia 2010;53:2480-6.

35. Chen S, Zhang Q, Dai G, Hu J, Zhu C, Su L, et al. Association of depression with pre-diabetes, undiagnosed diabetes, and previously diagnosed diabetes: a meta-analysis. Endocrine 2016;53:35-46.

36. van Harten B, de Leeuw FE, Weinstein HC, Scheltens P, Biessels GJ. Brain imaging in patients with diabetes: a systematic review. Diabetes Care 2006;29:2539-48.

37. Gold SM, Dziobek I, Sweat V, Tirsi A, Rogers K, Bruehl $\mathrm{H}$, et al. Hippocampal damage and memory impairments as possible early brain complications of type 2 diabetes. Dia- betologia 2007;50:711-9.

38. Sapolsky RM. Depression, antidepressants, and the shrinking hippocampus. Proc Natl Acad Sci U S A 2001;98:12320-2.

39. Lyoo IK, Yoon SJ, Musen G, Simonson DC, Weinger K, Bolo N, et al. Altered prefrontal glutamate-glutamine-gamma-aminobutyric acid levels and relation to low cognitive performance and depressive symptoms in type 1 diabetes mellitus. Arch Gen Psychiatry 2009;66:878-87.

40. Korczak DJ, Pereira S, Koulajian K, Matejcek A, Giacca A. Type 1 diabetes mellitus and major depressive disorder: evidence for a biological link. Diabetologia 2011;54:248393.

41. Reutrakul S, Thakkinstian A, Anothaisintawee T, Chontong $\mathrm{S}$, Borel AL, Perfect MM, et al. Sleep characteristics in type 1 diabetes and associations with glycemic control: systematic review and meta-analysis. Sleep Med 2016;23:2645.

42. Luyster FS, Dunbar-Jacob J. Sleep quality and quality of life in adults with type 2 diabetes. Diabetes Educ 2011;37:347-55.

43. Warren RE, Deary IJ, Frier BM. The symptoms of hyperglycaemia in people with insulin-treated diabetes: classification using principal components analysis. Diabetes Metab Res Rev 2003;19:408-14.

44. Van der Does FE, De Neeling JN, Snoek FJ, Kostense PJ, Grootenhuis PA, Bouter LM, et al. Symptoms and wellbeing in relation to glycemic control in type II diabetes. Diabetes Care 1996;19:204-10.

45. Ciechanowski PS, Katon WJ, Russo JE, Hirsch IB. The relationship of depressive symptoms to symptom reporting, self-care and glucose control in diabetes. Gen Hosp Psychiatry $2003 ; 25: 246-52$. 